Revista de Derecho

Universidad Católica del Norte

Sección: Estudios

Año 18 - No 2, 2011

pp. $73-101$

\title{
ROL Y PODERES DEL JUEZ CIVIL: UNA MIRADA DESDE LA EFICIENCIA DEL PROCESO
}

\section{IVÁN HUNTER AMPUERO*}

RESUMEN: El presente trabajo tiene por objeto mostrar la estrecha vinculación entre poderes del juez y eficiencia del proceso. Para cumplir este cometido se ha querido comenzar asumiendo una determinada concepción acerca del fin del proceso civil basada en la justicia de la decisión, que toma como condición necesaria pero no suficiente la verdad de los hechos. Junto a dicha finalidad se agregan otras como la de un proceso de bajo costo y en un tiempo razonable. En la necesidad de hacer compatible esas finalidades los poderes del juez juegan un papel central, conduciendo el proceso a un resultado justo y en un tiempo adecuado, permitiendo además aplicar libremente el derecho - previo contradictorio- cuando este ha sido mal invocado, impidiendo que la actividad jurisdiccional se frustre por cuestiones jurídicas.

PALABRAS CLAVE: Poderes del juez - eficiencia del proceso - decisiones justas - verdad procesal.

\section{ROLE AND AUTHORITY OF THE CIVIL JUDGE: A LOOK FROM THE EFFICIENCY OF THE PROCESS}

ABSTRACT: This article intends to show the close connection between judge's authority and the process efficiency. In order to achieve this goal we have begun assuming a certain conception regarding the end of the civil process based in the justice of the decision that takes as a necessary, but not enough, condition: the truth of the facts. Together with said aim there are others such as a low cost process and done in a reasonable time. In the need to make these aims compatible the judge's authority plays a central role, leading the process to a fair

Abogado, Doctor en Derecho por la Universidad Carlos III (España) y Magíster en Derecho, Universidad Austral (Chile). Profesor de Derecho Procesal de la Universidad Austral de Chile. Este trabajo fue realizado en el marco y con el financiamiento de la Dirección de Investigación y Desarrollo de la Universidad Austral de Chile (DID), proyecto $\mathrm{N}^{\circ}$ 2010-12 (2010-2011), titulado "El rol del juez en el Proyecto de Código Procesal Civil", del cual el autor de este trabajo es su investigador responsable. Correo electrónico: ivanhunter@uach.cl Fecha de recepción: 31 de marzo de 2011.

Fecha de aceptación: 17 de mayo de 2011. 
result and in adequate timing, also allowing to freely apply the law - prior contradictory- when it has been wrongly cited, preventing the jurisdictional activity to fail for juridical reasons.

KEY WORDS: Judge's authority - process efficiency - just decisions procedural truth.

\section{INTRODUCCIÓN}

A diferencia de la justicia penal que alcanzó un adecuado desarrollo dogmático previo y postreforma, el proceso civil no ha tenido tiempo para sentarse a reflexionar acerca de los lineamientos centrales que deben orientar su transformación. Si bien el Proyecto de Código Procesal Civil (en adelante PCPC) fue despachado al Congreso nacional con un diagnóstico claro en torno a la necesidad de la reforma, no tuvo una suficiente maduración ideológica acerca de cuáles serían los pilares sobre los que se asentaría el proceso civil. Esto último es particularmente grave si se piensa en el carácter general y supletorio que está llamado a servir el procedimiento civil ordinario.

Desde esta perspectiva, me parece necesario sostener que el punto de arranque de cualquier discusión acerca de la reforma al proceso civil es la definición de cuál es el rol que debe cumplir el juez, si es que realmente estamos dispuestos a adjudicarle alguna función diferente a la de resolver la controversia. La determinación de ese rol, necesariamente, vendrá acompańada de una respuesta acerca de los poderes que debe tener el juez en el desarrollo de la actividad jurisdiccional. Es evidente que la aproximación que se haga a una interrogante de este tipo no es necesariamente desinteresada, puesto que supone una opción de política procesal de gran relevancia. Por ende, me atrevo a sustentar que frente a los fines que debe intentar aproximarse el proceso civil no cabe otra figura que la de un juez activo, provisto de los poderes necesarios para alcanzar una decisión justa -basada en la verdad-, en un tiempo razonable, con estricta sujeción al procedimiento legalmente previsto y con el menor costo posible para el Estado y el ciudadano.

Las próximas líneas están destinadas a sentar algunas ideas acerca del rol que debería desempeñar el juez en el proceso civil y, consecuentemente, de los poderes que debería estar revestido en relación a esa función. Para tal objetivo me propongo, en primer lugar (1), precisar por qué es necesario preguntarse por los fines del proceso civil, y describir las principales concepciones que la doctrina ha construido para sistematizar sus fines y explicar cómo la posición que se adopte entre los diversos modelos incide directamente en el reconocimiento e intensidad de los poderes del juez. En segundo lugar (2), pretendo describir brevemente las grandes 
concepciones asentadas por la doctrina en torno a la asignación de una finalidad al proceso civil, terminando este acápite justificando que el proceso debe orientarse a la toma de decisiones justas. Luego (3) pretende demostrar que los poderes del juez (probatorios, ordenatorios y de aplicación del Derecho) pueden justificarse en la consecución de los fines del proceso civil. En este afán daré cuenta de los principales poderes reconocidos al juez en el PCPC, explicando cómo su fundamento último puede reconducirse a estas ideas. Por último, finalizaré con las conclusiones.

\section{1) ¿POR QUÉ ES NECESARIO PREGUNTARSE POR LOS FINES DEL PROCESO CIVIL?}

La pregunta acerca de los fines del proceso civil puede venir precedida de dos objetivos que le dan sentido: el primero es servir de referente para comprender las normas que sustentan a un determinado sistema procesal. De ahí que el intérprete diga que tal o cuál norma se inspira en un determinado valor; por ejemplo, la economía procesal. Es indudable que la inteligencia de la lógica interna del proceso es una herramienta a la que puede recurrir el operador al momento de interpretar y aplicar la norma procesal. La segunda razón viene dada por la necesidad de plantear o formular algunos fines cuya consecución a través del proceso se estima relevante. Aquí, por ejemplo, la economía procesal sirve de criterio para validar una norma procesal. El primer objetivo se aboca a la tarea de desentrañar cómo la norma es y qué fin efectivamente persigue; mientras que el segundo se dedica a la tarea de definir cómo la norma debería ser para alcanzar esos fines propuestos; por tanto, a un discurso del tipo político procesal del cual pueden desprenderse buenas razones para preferir uno $\mathrm{u}$ otro modelo de proceso. Ambos enfoques son válidos aunque suelen plantearse en dos ámbitos diferentes. El primero en el de la dogmática jurídica -tan escasa en nuestros estudios procesales-, y el segundo en la propuesta de políticas públicas para el diseño procesal.

La pregunta en cuestión es válida y útil en la discusión del PCPC. La adjudicación de algún fin al proceso parece ser un tópico indispensable para el diseño de sus etapas, pero, sobre todo, para la definición y alcance de los poderes y facultades de las partes y del juez. Es imposible proyectar una reforma sin tener en cuenta los fines que se deben intentar alcanzar el proceso civil. Las diferentes técnicas procesales adquieren sentido cuando son puestas al servicio de un fin, y solo conociéndolo es posible discernir qué técnica es la adecuada o la más eficiente. Esta discusión creo que no se ha efectuado, o al menos no en el grado que se debería esperar de una reforma del calado como esta.

La discusión acerca de los fines y el rol del juez en el proceso civil resulta justificada si entendemos que estos fines pueden ser antagónicos 
y estar condicionados por la vigencia de los derechos fundamentales de índole procesal. Esto es un problema inherente a cualquier reforma. Por lo general, los modelos teóricos no permiten ser concretados en normas jurídicas de manera total, y requieren modulaciones importantes cuando se enfrentan a otros modelos o valores. Así, las reglas jurídicas, suelen recoger soluciones de transacción que suponen una ponderación legislativa en orden a preferir un determinado fin sacrificando parcialmente otro. Lo mismo vale cuando se tenga que decidir el grado satisfacción de un fin cuando los derechos del ciudadano impidan o mermen la posibilidad de alcanzarlo íntegramente.

Siendo esto cierto entonces la discusión acerca del fin del proceso como condición previa y necesaria de cualquier discusión de su articulado resulta esencial. No me parece, sin embargo, que este esfuerzo se haya efectuado con la profundidad que merece. En consecuencia, una indagación como la que aquí se propone resulta indispensable para el ámbito de los poderes del juez.

\section{2) LOS FINES DEL PROCESO CIVIL Y LA DISTRIBUCIÓN DE ROLES}

En la doctrina tradicional es frecuente reconocer - a grandes rasgos-, dos grandes tendencias en orden a los fines que debe perseguir el proceso civil. Se trata de simplificaciones de sistemas que recogen realidades mucho más complejas y de múltiples aristas que suelen postularse en extremos opuestos, aun cuando también es posible sustentar su complementariedad. Estas grandes concepciones influyen directamente en el papel que juega la judicatura en el ejercicio dinámico de la jurisdicción, de tal manera que el binomio rol-poderes del juez está estrechamente relacionado con la finalidad que se le adjudique al proceso civil.

Los poderes del juez civil están en íntima conexión con el fin que se proponga del proceso civil; no obstante, la intensidad de esos poderes siempre es posible situarla en una escala, donde algunos sistemas preferirán una mayor participación del juez en la actividad procesal, mientras otros lo reducirán a lo estrictamente necesario aun cuando tienen identidad de fines.

Frente a estos fines es posible situar a otros concurrentes que pueden complementarlo. Es el caso, por ejemplo, de la economía procesal que puede ser un fin del proceso que concurra con cualquiera de otros.

\section{(2.1) LA RESOLUCIÓN DE CONTROVERSIAS COMO FIN DEL PROCESO CIVIL}

Una primera aproximación es la que brinda aquel modelo que otorga al proceso civil la única finalidad de resolver conflictos jurídicamente 
relevantes. Para este modelo el proceso civil debe cumplir una función eminentemente pragmática puesto que se destina a lograr la paz social mediante la extirpación del conflicto ${ }^{1}$. En este aspecto el proceso se orientaría básicamente a la obtención de la certeza jurídica por medio de la cosa juzgada, no exigiendo a la decisión ninguna condición especial, más allá de las estrictamente procesales (requisitos formales y plazo de dictación). Así, la eficacia del proceso judicial estaría dada por la eliminación definitiva de la incerteza en la titularidad de una relación jurídico-material, y la composición pacífica de una controversia entre sujetos particulares.

En este escenario la calidad y justicia de la decisión no serían en absoluto relevantes para que el proceso cumpla su función, y son más bien valores agregados pero de segundo orden, cuya obtención no será necesaria para legitimar la decisión. Tanto la decisión ilegal como aquella que se asienta en bases fácticas no reales, son eficaces y cumplen con la misión a que se destina el proceso $^{2}$. En cierta medida la certeza y seguridad jurídica que se alcanza con esa decisión judicial tiene un carácter exclusivamente formal, esto es, goza de independencia respecto a su acierto ${ }^{3}$. Se trata de un fin eminentemente pragmático donde lo esencial es asegurar a los ciudadanos el desarrollo de un procedimiento justo, y no necesariamente una decisión justa.

Esta primera concepción está unida a dos dogmas que condicionan la posición y rol del juez en el proceso civil ${ }^{4}$. El primero es la necesidad de proteger la imparcialidad del juez. Esta concepción entiende que dotar al juez de poderes en el ámbito probatorio implica despojarlo de su necesaria imparcialidad, de manera que el legislador se debe reducir al mínimo la intervención del órgano jurisdiccional en el ámbito de la prueba. Si el proceso se mira únicamente como un procedimiento para solventar contiendas entonces es claro que el juez ningún rol relevante puede jugar que no sea el de resolverla. Se rechaza, de igual forma, que la verdad sea un fin u objetivo alcanzable por medio del proceso, sustituyendo gnoseológicamente lo "verdadero" por lo "probable" 5 .

1 Moreno, Víctor; Contés, Valentín (2004) Introducción al Derecho Procesal. Valencia: Tirant lo Blanch, 319 pp., p. 46.

2 Taruffo, Michele (2009) Páginas sobre la justicia civil. Madrid: Marcial Pons, 599 pp., p. 247.

3 Cortés, Valentín (1983): “La eficacia del proceso de declaración”. En Constitución, Derecho y Proceso. Estudios en memoria de los profesores Vicente Herche Quemada y Ángel Duque Barragues. Zaragoza: Facultad de Derecho Universidad de Zaragoza, pp. 385-408, p. 387.

4 Díaz Cabiale, José Antonio (1996) Principios de aportación de parte y acusatorio: la imparcialidad del juez. Granada: Editorial Comares, 578 pp., p. 417.

5 Díaz (1996) 417. Para este autor la sustitución de este concepto obedece a una relativización del valor verdad en el proceso, de manera que el proceso debe orientarse a la obtención de aquello que "probablemente" sucedió, y no lo que "verdaderamente" fue. De esta forma, el juez debe quedarse como un mero espectador de un combate entre dos sujetos. 
Esta concepción tiene importantes repercusiones en el ámbito probatorio, donde la actividad de las partes juega un rol central en la conformación del contenido de la decisión. Explica Baur ${ }^{6}$ que en un sistema como este el procedimiento probatorio (iniciativa, admisión y práctica de la prueba) tenderá indefectiblemente hacia la generación de cargas procesales para los litigantes, reduciendo al máximo la participación del juez en el ámbito de la prueba. Si la verdad no juega ningún papel relevante en la decisión entonces tampoco es necesario dotar al juez de poderes en el ámbito de la actividad probatoria, puesto que estos se justifican en la medida que las decisiones judiciales deban acercase a la verdad para ser consideradas justas y cumplir la finalidad del proceso ${ }^{7}$. Así entonces si el resultado de la prueba no coincide con la verdad es completamente irrelevante; por ende, el procedimiento probatorio carece de mecanismos destinados a disminuir el margen de error derivado de la falta o insuficiencia en el material probatorio, asumiendo la carga de la prueba un rol central en el momento de la adjudicación judicial.

El segundo dogma que respira ínsito en esta doctrina atañe a la naturaleza privada del objeto del proceso civil. Al igual que el funcionamiento del mercado el proceso es visto como un sistema autosuficiente capaz de satisfacer de la manera más adecuada los intereses privados libremente contrapuestos, sin necesidad que el Estado intervenga. El proceso, bajo este perfil, debe fomentar el libre juego de los litigantes que desde sus homólogas posibilidades de acciones y defensas lo llevan a un resultado óptimo, similar al que brinda el juego de la oferta y la demanda. La intervención del Estado por medio del juez generaría una distorsión en la satisfacción de los intereses particulares ${ }^{8}$.

El fin pragmático del proceso civil fue llevado a sus extremos durante el siglo XIX, expandiéndose no solo a la irrelevancia de la decisión para

6 Baur, Fritz (1980) La socialización del proceso. Salamanca: Publicaciones del Departamento de Derecho Procesal de la Universidad Salamanca, pp. 7-24, p. 10.

7 Otra arista de esta postura estima que sí es posible alcanzar la verdad en las decisiones judiciales, pero postulan que el único método para lograrla es el libre juego dialéctico en materia probatoria. Son las partes las que deberían alcanzar esa verdad a través de la dialéctica procesal, mecanismo que incentiva agregar al proceso todo el material probatorio jurídicamente relevante. Desde luego que en esta postura se advierte una contradicción o al menos una diferencia conceptual acerca de la noción de verdad. O la verdad es aquella que nace del libre juego dialéctico de las partes, lo que equivale a decir que es la que el juez declara en la sentencia como fruto de esa actividad; o bien, es necesaria alcanzarla, en cuyo caso se debe asumir que la iniciativa probatoria de los litigantes puede no ser suficiente. Véase: Díaz (1996) 418.

8 Díaz Cabiale, con certeza precisión explica que "así al igual que el mercado se justifica como un sistema autosuficiente para satisfacer de la manera más adecuada los intereses privados, sin necesidad de intervención estatal, el proceso resulta ser el lugar idóneo para que el juego de las partes, al presentar el aspecto de la realidad más favorable a sus intereses, permita alcanzar el resultado más justo sin necesidad de que el órgano jurisdiccional indague o practique actividad probatoria”. Véase: Díaz (1996) 418. 
los fines de la justicia sino también a los aspectos netamente procesales que quedaron entregados a la libre iniciativa de los litigantes. Las principales codificaciones europeas y latinoamericanas pusieron el centro de atención en el derecho subjetivo y la igualdad formal como ejes centrales en la construcción e interpretación de las normas procesales ${ }^{9}$. Desde este punto de vista, el principio dispositivo fue interpretado en un sentido lato, por el cual los ciudadanos podían disponer de modo absoluto de sus derechos subjetivos e intereses objeto de la tutela jurisdiccional, y además, producto de esa disponibilidad, de los actos del proceso. El referido principio comprendía tanto la esfera material de la tutela jurisdiccional (relación jurídico-material) como el cauce por el cual el Estado prestaba la tutela (relación jurídico-procesal) ${ }^{10}$.

Se comprenderá que en este modelo el papel de la judicatura está francamente condicionado por el carácter eminentemente privado del objeto de la tutela ${ }^{11}$. Cuando la disputa judicial recae sobre bienes disponibles se estima que el óptimo de asignación de esos bienes tiene que ser alcanzado a través del libre juego los de litigantes. Al legislador le toca asegurar una distribución igualitaria de oportunidades procesales y al juez garantizar que las partes estén en la posibilidad de utilizarlas. Así entonces lo únicamente relevante para estar concepción es que el procedimiento sea considerado justo, y no necesariamente su decisión. Se incrusta en el proceso una idea de justicia procedimental, donde la justicia de una decisión depende exclusivamente de la justicia del procedimiento.

Una de las características principales de estos sistemas es la alta tipicidad al momento de consagrar los escasos poderes a los jueces. El legislador determina detalladamente y en forma previa, tanto los presupuestos como las condiciones de ejercicio y límites de esos poderes probatorios. La iniciativa del juez se presenta como una actividad eminentemente reglada, rígida y con escaso margen de flexibilidad. Las reglas legales junto

9 Véase: Devis, Hernando (1985): "Facultades y deberes del juez en el moderno proceso civil”. En Estudios de Derecho Procesal, Buenos Aires: Zavalia Editores, pp. 257-311, p. 255.

10 Cabe precisar que esta escisión cayó a principios del siglo XX cuando la doctrina -siguiendo esencialmente el pensamiento de Liebman- separó, por un lado, el derecho exclusivo de las partes de proponer el proceso y de pedir la tutela jurisdiccional, de otra regla de la iniciativa de las partes en la instrucción de la causa. El primero, conocido como principio dispositivo coloca su atención en la titularidad de los particulares sobre los derechos objeto del proceso y el segundo, por el contrario, conocido como principio de aportación de parte se enfoca al desarrollo formal del proceso. Véase: Liebman, Tulio (1960). "Fondamento del principio dispositivo". Rivista di Diritto Processuale, No 4, pp. 551-565, pp. 551 y 552.

11 Los derechos de corte individual y económico como la propiedad y la libre iniciativa empresarial se reflejaron intensamente en el ámbito específico de la judicatura a través de las nociones de acción y jurisdicción en materia civil y comercial; por ende, el juez debía ser totalmente pasivo, carente de iniciativa de impulso frente a la actividad de los litigantes y, al mismo tiempo, no debía gozar de ningún tipo de herramienta para investigar la verdad. Véase: Devis, Hernando (1967). "La iniciativa probatoria del juez en el proceso contemporáneo”. Revista Iberoamericana de Derecho Procesal, No 4, pp. 637-662, p. 637. 
con legitimar la actividad probatoria ex officio buscan acotarla lo máximo posible. Estos sistemas reconocen al juez una libertad de actuación, es decir, un ámbito donde el órgano es libre para ejercitar o no sus poderes, pero respetando íntegramente sus presupuestos y límites, de manera de evitar el temido campo de lo discrecional ${ }^{12}$.

En el ámbito técnico la decisión por un modelo como este tiende a reforzar el ejercicio de las facultades de las partes en desmedro de la actividad del juez. El denominado principio de aportación de parte, por el cual la introducción de los hechos y la proposición de los medios para acreditarlos corresponden a los litigantes ${ }^{13}$, es exacerbado por medio del contradictorio, que se convierte en la única forma de legitimar la decisión judicial. De igual forma, la carga de la prueba es considerada un mecanismo legítimo e indispensable para la resolución de los conflictos, no habiendo ninguna herramienta destinada a atenuar su aplicación final.

Con algunas atenuantes se podría sustentar que obedece a este modelo el proceso civil español de la LEC 1/2000, que se declaró decididamente partidario del principio de aportación de parte, reduciendo, aunque no eliminando, la participación del juez en la recolección del material probatorio ${ }^{14}$. En este aspecto el juez puede simplemente advertir a las partes la insuficiencia de la prueba propuesta y sugerir la práctica de alguna probanza (Art. 429. 1 de la LEC) ${ }^{15}$. Fuera de esta potestad y las denominadas "Diligencias finales", el juez no cuenta con mayor participación

12 Díaz (1996) 15.

13 Picó i Junoy, Joan (1996). El derecho a la prueba en el proceso civil, Barcelona: Bosch Editor, 446 pp., p. 214.

$14 \quad$ El Mensaje de la LEC española señala: "La nueva Ley de Enjuiciamiento Civil sigue inspirándose en el principio de justicia rogada o principio dispositivo, del que se extraen todas sus razonables consecuencias, con la vista puesta, no solo en que, como regla, los procesos civiles persiguen la tutela de derechos e intereses legítimos de determinados sujetos jurídicos, a los que corresponde la iniciativa procesal y la configuración del objeto del proceso, sino en que las cargas procesales atribuidas a estos sujetos y su lógica diligencia para obtener la tutela judicial que piden, pueden y deben configurar razonablemente el trabajo del órgano jurisdiccional, en beneficio de todos." Luego continúa expresando: "De ordinario, el proceso civil responde a la iniciativa de quien considera necesaria una tutela judicial en función de sus derechos e intereses legítimos. Según el principio procesal citado, no se entiende razonable que al órgano jurisdiccional le incumba investigar y comprobar la veracidad de los hechos alegados como configuradores de un caso que pretendidamente requiere una respuesta de tutela conforme a Derecho. Tampoco se grava al tribunal con el deber y la responsabilidad de decidir qué tutela, de entre todas las posibles, puede ser la que corresponde al caso."

15 En el ámbito de la doctrina española se ha forjado una intensa discusión en torno al contenido y alcance de esta potestad judicial, estimándose contraria a la inspiración de la LEC que tiende a reforzar el principio de aportación de parte en todos sus extremos. Para un análisis de las principales doctrinas y discusiones, véase: Abel Lluch, Xavier (2005) Iniciativa probatoria de oficio en el proceso civil. Barcelona: Editorial Bosch, 472 pp., pp. 121 a 123, y Picó i Junoy, Joan (2007) El juez y la prueba, Estudio de la errónea recepción del brocardo iudex iudicare debet secundum allegata et probata, non secundum concientiam y su repercusión actual. Barcelona: Bosch Editor, 394 pp., p. 124. 
en la recolección inicial del material probatorio. Las únicas excepciones vendrían dadas en los juicios no dispositivos, donde, por el contrario, el legislador español optó por reconocerle al juez un poder amplio de iniciativa probatoria.

\section{(2.2) LA DECISIÓN JUSTA COMO FINALIDAD DEL PROCESO CIVIL}

Tal como lo habíamos indicado, si se considera que la función del proceso es la de resolver controversias eliminando el conflicto surgido entre los privados, se tiende a excluir que la determinación verdadera de los hechos sea un valor y, en consecuencia, se niega que sea una de las finalidades fundamentales del proceso.

Frente a esta visión se ha postulado otra que entiende que el proceso es un mecanismo de tutela y garantía de los derechos subjetivos e intereses legítimos mediante la actuación del orden jurídico. El Estado no saca nada con reconocer al ciudadano la titularidad de un derecho o interés sino lo garantiza jurisdiccionalmente. En consecuencia, si la consagración de un derecho es consustancial a su protección, entonces el proceso civil debe orientarse a obtener decisiones justas basadas en la verdad, puesto que esta sería la única forma de tutelar efectivamente los derechos de los ciudadanos.

Hay un claro apego a la denominada "ideología legal-racional" de la decisión, por la cual la decisión para ser considerada justa no debe estar fundada sobre una reconstrucción injusta o inatendible de los hechos. Así la justicia de la decisión toma como condición necesaria aunque no suficiente, la verdad o realidad de los hechos. En este contexto la prueba juega un papel fundamental en la legitimación del proceso, y es considerada un método de conocimiento racional que busca suministrar al juez datos o informaciones acerca de unos hechos pasados cuya fidelidad en su reconstrucción es indispensable para resolver adecuadamente el conflicto. La prueba asume una función epistemológica o demostrativa.

En esta perspectiva, el proceso se orienta a maximizar las posibilidades de que aquello que efectivamente sucedió se aproxime en términos de correspondencia con lo que el juez declara probado en el proceso; por ende, el procedimiento probatorio tenderá a disminuir los límites de la tolerabilidad del error en materia de prueba y maximizará las posibilidades del empleo de los elementos de convicción como instrumento de verificación del juez ${ }^{16}$. Consustancial a esta idea es la posibilidad de que las partes hagan una amplia utilización de su derecho a aportar prueba y que, al mismo tiempo, se tienda a reforzar los poderes del juez en ese ámbito.

16 Taruffo, Michele (1990). "Modelli di prova e di procedimento probatorio". Rivista di Diritto Processuale, $\mathrm{N}^{\circ} 2$, pp. 420-448, pp. 445 y ss. 
De lo dicho surgen dos interrogantes: ¿qué verdad intenta alcanzar este modelo? ¿A qué verdad se refiere? Desde luego que cuando se hace referencia a la verdad como finalidad probatoria se debe descartar a la verdad absoluta, que parece ser un concepto al que frecuentemente se recurre cuando se quiere impugnar esta finalidad de la prueba ${ }^{17}$. Este tipo de verdad supone que el enunciado fáctico introducido por la parte debe ser necesariamente verdadero, lo que es imposible determinarlo en un proceso judicial y aún fuera de él. Constituye un error entender la relación entre prueba y verdad en términos de prueba y verdad absoluta. Esta última no es posible alcanzarla en ninguna parcela del conocimiento humano ni siquiera en las denominadas ciencias duras, como la matemática o física, y parece estar entregada a los terrenos de la religión y la metafísica $^{18}$.

Al contrario, creo que la justa posición de la verdad en el proceso civil pasa por comprender la distinción entre la verdad de un enunciado fáctico con la declaración de que un enunciado deba ser considerado verdadero ${ }^{19}$. Así, un enunciado fáctico es verdadero "cuando los medios de prueba incorporados al proceso aportan elementos de juicio suficientes a favor de la verdad de una proposición (lo que no debe confundirse que la proposición sea verdadera)" 20 . Por consiguiente, la verdad del enunciado de hecho (por ejemplo, que A contamina culposamente y que debe responder) es irrelevante si se dispone de elementos de información que confirman y dan por verdadero ese enunciado de hecho (hay pruebas suficientes que A contamina culposamente, por ende, es verdadero que A contamina).

Se trata, por consiguiente, de una verdad relativa derivada de la extensión y utilidad de las pruebas disponibles ${ }^{21}$, única a la que se puede aspirar en un proceso judicial que es un contexto epistemológicamente

17 Así, Montero Aroca, Juan (2000): "Nociones generales sobre la prueba (entre el mito y la realidad". En La prueba. Madrid: Consejo General del Poder Judicial, pp. 15-66, p. 25 y Moreno Catena, Víctor (2001): "Comentario al Art. 282 de la Ley de Enjuiciamiento Civil 1/2000”. En Escribano Mora (coordinador). El Proceso Civil, Vol. II, 6700 pp., p. 2179.

18 Véase: Taruffo, Michele (2008) La prueba. Madrid: Marcial Pons, 324 pp., p. 26.

19 Como explica Ferrua, la prueba de los hechos se obtiene solo al interior del proceso, pero la verdad o falsedad de las proposiciones que lo afirman es independiente del proceso; la distinción entre lo es verdadero y lo que viene a ser considerado verdadero, es esencial para la noción de verdad. Ferrua, Paolo (2007). Il 'giusto processo', $2^{\circ}$ Edición, Bolonia: Zanichelli, 246 pp., p. 72.

20 Ferrer, Jordi (2005) Prueba y verdad en el Derecho. Madrid: Marcial Pons, 111 pp., pp. 74 y 75 .

21 TARuffo, Michele (2003). "Algunos comentarios sobre la valoración de la prueba". Discusiones (Publicaciones periódicas), $\mathrm{N}^{\circ} 3$, pp. 81-97, p. 87. Para un análisis más exhaustivo y detallado de las refutaciones a la tesis contraria a la obtención de la verdad dentro del proceso puede verse: Taruffo, Michele (2009) La prueba de los hechos. $3^{a}$ edición. Madrid: Editorial Trotta, 542 pp., pp. 56 a 87. 
imperfecto $^{22}$. Es lógico que esas imperfecciones (limitaciones a la utilidad epistémicas de las pruebas) puedan incidir en el grado de verdad, confianza, probabilidad o certeza que puede ser atribuido a los enunciados de hecho, pero no excluyen que a través de la prueba sea posible determinar la verdad o falsedad de estos enunciados ${ }^{23}$.

Así entonces el juicio de hecho se concibe como una elección entre los diferentes discursos narrativos racionalmente presentados por las partes y que pueda sostenerse con mayores elementos de confirmación, esto es, no hay una verdad absoluta sino una más probable ${ }^{24}$.

\section{(2.2.1) ¿Qué motivaciones puede tener el legislador para orientar el proceso hacia la obtención de decisiones justas?}

La tutela jurisdiccional de un derecho o interés legítimo es solo formal si el proceso no logra acercarse a una decisión justa. Y una decisión

22 Ferrer distingue al efecto tres tipos de reglas que pueden impedir que el juez llegue a la verdad de los enunciados fácticos: las primeras dicen relación con el marco donde se desarrolla la actividad probatoria, es decir, el proceso judicial, que impone ciertos límites y peculiaridades a la prueba (por ejemplo, que la prueba deba rendirse en una oportunidad precisa, la posibilidad que las partes omitan la presentación de un medio de prueba que pueda perjudicarlos, etc.). Una segunda limitación en la relación de prueba y verdad es la institución de la cosa juzgada, que pone término a la discusión jurídica a través del proceso judicial. La tercera limitación es aquella que deriva de las reglas jurídicas sobre la prueba, ya sea de las reglas que se refieren a la actividad probatoria, a los medios de prueba y al resultado probatorio. Véase: Ferrer (2005) 63 a 68. También puede consultarse: Gascón, Marina (2004) Los hechos en el derecho. Bases argumentales de la prueba. Madrid: Marcial Pons, 232 pp., pp. 125 y siguientes, y Cavallone, Bruno (1991) Il Giudice e la prova nel processo civile. Padova: Cedam, 560 pp., pp. 947 a 950, quien manifiesta que la regulación inevitable de toda la instrucción probatoria representa un obstáculo al establecimiento judicial de la verdad.

23 Taruffo, Michele (2002). "Consideraciones sobre prueba y verdad". Derecho y Libertades Revista del Instituto Bartolomé Las Casas. N 2, año VII. Madrid: Universidad Carlos III de Madrid. Boletín Oficial del Estado, pp. 99-124, p. 116. Esta concepción, por cierto, igual goza de algunos detractores. En efecto, cierta parte de la doctrina ha impugnado que la búsqueda de la verdad sea la finalidad de la prueba, y de paso, sostienen que no puede legitimarse la potestad probatoria del tribunal en la obtención de la misma. Se ha dicho por esta posición doctrinal que se debe renunciar a la búsqueda de la verdad dentro del proceso civil, y ello en atención a los siguientes motivos: a).- Los hechos no afirmados por alguna de las partes no existen para el juez, quien no puede desarrollar una actividad de búsqueda de los mismos; b).- Los hechos afirmados por ambas partes, o afirmados por una y admitidos por otra existen y no pueden ser desconocidos; c).- La actividad probatoria respecto a los hechos controvertidos es simplemente verificadora y no investigadora. Se agrega que la prueba se desarrolla dentro de un contexto de reglas adjetivas que impiden la obtención de la verdad, como se manifiesta en la posibilidad de decretar la inadmisibilidad probatoria y en la proscripción de la prueba ilícita. Véase, por todos, Montero Aroca, Juan (2001) Los principios políticos de la nueva ley de Enjuiciamiento Civil. Los poderes del juez y la oralidad. Valencia: Tirant lo Blanch, 190 pp., p. 107 y siguientes, quien a mi juicio efectúa un sencillo pero comprensivo análisis de las principales críticas que se plantean a la obtención de la verdad como finalidad de la prueba

24 Así lo entienden: Gascón (2004) 45, y Bonet NAVArro, José (2009) La prueba en el proceso civil. Cuestiones fundamentales. Valencia: Difusión Jurídica, 361 pp., p. 48. 
puede ser considerada justa, únicamente, cuando se corresponde con la verdad de los hechos. Me adscribo, por tanto, a una teoría muy difundida en parte de Europa y nuestro país, denominada "teoría de la justicia de la decisión" 25 y que descansa en razones de evidente lógica: "parece, en efecto, intuitivo que la norma será aplicada injustamente, y sería, pues, violada, si las consecuencias que prevé se adjudicaran a un caso en que el hecho condicionante no se hubiere producido" 26 .

Si las consecuencias de las reglas jurídicas dependen de la verificación de los presupuestos de hecho previstos en la norma, parece razonable que una mayor aproximación a la verdad de tales supuestos fácticos permitirá lograr una correcta aplicación de la norma jurídica. La verdad no sería un fin del proceso sino una condición necesaria e indispensable para la decisión justa y legítima ${ }^{27}$.

La segunda razón que parece justificar la opción de orientar el proceso hacia la verdad es la necesidad de dotar a la valoración de la prueba de elementos racionales que la hagan susceptible de un control intersubjetivo y no infalible, cuestión que no se concibe bajo una concepción persuasiva o retórica de la prueba. En simples palabras, una concepción que vincula los hechos probados a postulados epistemológicos es compatible con la exigencia constitucional de motivación de las decisiones judiciales en cuanto exigencia de racionalidad ${ }^{28}$. Como lo explica Taruffo "la verdad

25 Término acuñado por: TARuffo, Michele (2002) "Idee per una teoria della decisione giusta”. Sui Confini. Scritti sulla giustizia civile, Bolonia: Il Mulino, pp. 219-234, pp. 224 y 225. TARUfFo (2009) 67. TARUfFo (2008) 22.

Carratta, Antonio (2001). "Funzione demostrativa della prova (verità del fatto nel processo e sistema probatorio". Rivista di Diritto Processuale. N 1 , pp. 73-103, pp. 79 y 86, Señala que solo un procedimiento probatorio de tipo racional permite el control del razonamiento en forma externa, por las partes, el juez de la impugnación y la sociedad en general. En este sentido, afirma, que el resultado de la prueba para la función demostrativa debería ser válido para la razón de todo ser humano racional, mientras que para la visión subjetivista el resultado de la prueba es válido solo para la credibilidad de tal juez. Véase en idéntico sentido: JaÉn VAllejo, Manuel (1989). "El criterio racional en la apreciación de la prueba". Revista de Derecho Procesal. No 1, pp. 69-80, p. 69, quien criticando la tendencia inicial del Tribunal Supremo Español de entender un concepto subjetivo de la libre apreciación de la prueba, es categórico en afirmar que un criterio racional en la valoración es el único que permite la posibilidad de control del razonamiento que efectúa el órgano de la instancia.

Quizá la mayor muestra de sinceridad acerca de imposibilidad de motivar una sentencia sobre la base del convencimiento del juez es la que expone De la Oliva, Andrés (2004) Derecho Procesal Civil. El proceso de declaración. $3^{\text {a }}$ ed., Valencia: Editorial Universitaria Ramón Areces, 681 pp., p. 465, quien afirma que "no es razonable imponer a los órganos jurisdiccionales que expresen en sus sentencias lo que pertenece a los internos procesos psicológicos de convicción, muchas veces parcialmente objetivables, sí, pero también parcialmente pertenecen al ámbito de lo inefable." Una concepción como esta es claramente inaceptable en un modelo de adjudicación judicial que permita a las partes utilizar la prueba como herramienta para la defensa de sus intereses. Uno de los rasgos distintivo del Estado de Derecho es que el órgano jurisdiccional debe dar una respuesta racional a la petición de tutela que formula el justiciable, con el objeto de descartar la arbitrariedad de la decisión y legitimar el 
de los hechos no es el resultado de una actividad inescrutable que se desarrolla al interior del juez (...) sino que es el producto de una labor de conocimiento que se estructura en pasos cognoscibles y controlables, como el acopio de información, la comprobación de su fiabilidad, el análisis de su relevancia y la formulación de inferencia lógicamente válidas que se conducen a conclusiones justificadas racionalmente" 29 . De esta manera, la verdad no asoma de manera misteriosa sino que es fruto de un procedimiento cognoscitivo estructurado y racional, susceptible de ser controlado y compartido entre los sujetos ${ }^{30}$.

El tercer motivo está vinculado a razones pragmáticas acerca del funcionamiento del ordenamiento jurídico como mecanismo motivador de conductas. Todo conflicto social es resuelto aplicando normas previamente discernidas por la voluntad política de una comunidad. Cuando los individuos no son capaces de autocomponer sus conflictos, el Estado concibe a la jurisdicción como el momento de reconstrucción -ahora en el caso concreto- de la voluntad política antes manifestada en la norma jurídica. $\mathrm{Y}$ es actividad, para ser el exacto reflejo del orden que la comunidad ha querido darse, requiere la determinación de la verdad de los enunciados que sirven de base a la aplicación de la norma jurídica. Si la adjudicación judicial se sustenta en hechos que no han ocurrido estará distorsionando un orden previamente discernido, dando o negando un derecho a un sujeto a quien la comunidad no ha decidido dar o negar ese derecho. Además, va generando efectos perversos en la reafirmación del Estado de Derecho. El triunfo del derecho como medio de regulación de las conductas humanas depende, en gran término, de la capacidad de los tribunales de acercarse a la verdad cuando ha existido infracción a una norma jurídica. Solo hay incentivo al cumplimiento espontáneo del derecho si el proceso judicial se estructura hacia la determinación verdadera del caso sometido a su decisión, y fija de modo exacto quién ha cumplido y quién no ha cumplido con el mandato legislativo.

Por otro lado, la complejidad actual de las relaciones jurídicas y sociales impide mirar al fenómeno procesal de manera aislada suponiendo que únicamente existe un interés interpartes en la solución de un conflicto. La realidad muestra que los actores públicos y privados dirigen su mirada y se preocupan constantemente por lo que resuelven nuestros tribunales de justicia, y que las decisiones que ahí se toman suelen tener importantes repercusiones en las políticas públicas y en la distribución de los

sentido democrático de la función judicial. Si el juez no está en el deber de fundamentar sus decisiones porque el sistema le permite "acomodar su voluntad" a sus instintos y creencias, entonces la prueba, y hasta el proceso mismo, estarían de más.

29 Taruffo, Michele (2007). "Consideraciones entre prueba y motivación". Jueces para la democracia, No 69, pp. 73-80, p. 76.

30 TARUfFo (2007) 76 . 
recursos. Pensemos, por ejemplo, en los casos de responsabilidad patrimonial del Estado, donde el tribunal al resolver que el servicio no cumplió con el estándar exigido, está juzgando sobre la asignación más eficiente que ha hecho la administración de los recursos públicos. O cuando un tribunal determina que una empresa contamina más allá de lo permitido y que debe adoptar medidas de mitigación adicionales a las requeridas por la administración, agregando un costo a su cadena productiva con la consecuente repercusión en el precio final del bien o servicio. En ambos la necesidad de llegar a la verdad es indispensable si se considera que las decisiones judiciales se insertan en una complejidad de relaciones donde lo decidido en una situación puede tener repercusiones en otras. El sistema procesal civil se inserta en una cadena de decisiones que tienen repercusiones recíprocas, y que pueden llegar a modificar la adopción de otras decisiones públicas o/y privadas. En cierta forma, si el proceso civil logra acercarse a decisiones verdaderas no solo es más eficiente sino que hace del Derecho un instrumento más eficiente para motivar las conductas de los ciudadanos.

\section{3) LA EFICACIA Y EFICIENCIA DEL PROCESO CIVIL COMO JUSTIFICA- CIÓN A LOS PODERES DEL JUEZ CIVIL}

\section{(3.1) ¿EFICIENCIA PARA QUÉ?}

La pregunta por la eficiencia del proceso no puede contestarse sin recurrir a los fines. Un proceso no puede ser considerado eficiente o ineficiente por sí solo, sino en cuanto permite acercarse a un determinado objetivo que orienta la actividad procesal ${ }^{31}$. De ahí la importancia de adjudicar al proceso un determinado fin, puesto solo así es posible medir su eficiencia. Sin una finalidad no es posible medir la eficiencia y sin esta tampoco es posible alcanzar esa finalidad.

$\mathrm{Al}$ respecto me parece que la opción por un proceso orientado a la adopción de decisiones verdaderas es correcta por las razones que ya expusimos. Sin embargo, es imposible pensar este fin sin colocar otros a su lado. La realidad de los países es que la justicia es cara y la disponibilidad de los recursos destinados a satisfacerla es limitada. Por ende, alcanzar la verdad es una opción que en un proceso oral y público tiene un alto costo o al menos uno superior al de un proceso escrito. Lograr que el proceso se acerque a la verdad puede generar una serie de cargas pecuniarias para el litigante, puesto que la búsqueda de la información y la producción de todas las pruebas epistemológicamente relevantes constituyen un impor-

31 TARUfFo (2009) 247. 
te económico significativo. También puede haber costos para el Estado. Un proceso orientado a la verdad puede exigir una extensión temporal, al tener que concretarse más oportunidades para que se puedan buscar e introducir las fuentes de prueba disponibles, con el consecuente aumento en el gasto material, y el mayor dispendio para el erario al destinar más tiempo y recursos para la solución de un caso.

Se podrá apreciar que se trata de finalidades que pueden estar en pugna. Si una o ambas partes no están dispuestas a solventar los gastos asociados a la recolección y práctica de la prueba entonces la posibilidad de que la decisión que se adopte en ese proceso se funde en la verdad es mucho menor. Por ańadidura si de lo que se trata es que el proceso articule la mayor cantidad de etapas para ingresar $-y$, por ende, no excluirtodo tipo de material probatorio relevante y útil, entonces la posibilidad de que ese proceso se torne lento y engorroso es muy alta. Desde luego que ni el Estado ni el ciudadano común están en condiciones de asumir íntegramente los costos del proceso, máxime cuando el litigante, por lo general, no está comprometido con la decisión verdadera sino más bien con cualquier decisión que satisfaga sus intereses.

Desde esta perspectiva creo razonable entender que la eficiencia del proceso está definida por ese doble juego: por un lado, alcanzar la verdad como sustrato de aplicación de la norma jurídica, y; por el otro, constituirse como un cauce racional y económico que, sin olvidar su finalidad esencial, permita hacer frente a la demanda de justicia. Lograr el justo equilibrio en esta relación es una tarea compleja que exige un estándar elevado de justificación de la regla legal que se aleja de un valor para aproximarse al otro.

Es en esta relación donde calzan los poderes del juez al contribuir significativamente a alcanzar ambos fines. Tanto los que miran el gobierno externo del proceso como aquellos que influyen en el contenido de la decisión permiten acercase a los ideales de eficiencia en la consecución de los fines. A eso me dedicaré las líneas que siguen, es decir, a justificar que los poderes del juez permiten hacer del proceso una herramienta altamente eficiente.

\section{(3.2) PODERES PROBATORIOS DEL JUEZ Y EFICIENCIA DEL PROCESO}

Solo entendiendo que el proceso debe orientarse hacia la verdad es posible justificar la actividad probatoria del juez. Cuando el proceso busca únicamente resolver conflictos es evidente la articulación de una judicatura pasiva y carente de poderes en el orden probatorio. En esta última concepción es común observar que la prueba tiene un carácter persuasivo o retórico, que se orienta a lograr un estado mental o sicológico del sentenciador en torno a la verdad de un hecho. Por ende, no tendría por finalidad suministrar información al juez sobre unos datos para que sean 
comparados con las alegaciones de las partes sino que buscar convencer sicológicamente al juez que un hecho es cierto ${ }^{32}$.

Ahora bien, no debería generar mayores dificultades aceptar que la actividad desplegada por las partes en el proceso es parcial: cada litigante busca satisfacer los intereses que creen asistirle, por lo que su actividad probatoria irá encaminada directamente a ese fin. De esta forma, asumen una concepción persuasiva o retórica de la prueba, buscando convencer al juez para que acepte una decisión favorable a sus intereses.

Según esta idea es posible afirmar que las partes no asumen un papel cooperativo para descubrir la verdad, y hacen un juego de sumatoria cero para alcanzarla. Nada asegura que el choque libre de las fuerzas en litigio asegure la obtención o el mejor acercamiento de la verdad ${ }^{33}$. Las partes intentan satisfacer los umbrales que impone la carga de la prueba y, por regla general, no asumirán muchos riesgos en la actividad probatoria. En efecto, si desconocen el resultado que puede ofrecer una determinada fuente de prueba lo más probable es que se abstengan de ingresarla al proceso. Por ejemplo, si saben de la existencia de un testigo pero ignoran qué declarará lo más razonable es que no asuman el riesgo de citarlo a declarar. En simples palabras, merman la eficiencia del proceso.

Por otro lado, si las partes gozan de libertad para aportar los medios de prueba que estimen convenientes porque son titulares de un derecho de defensa, entonces no es legítimo que deban asumir tareas probatorias en perjuicio de sus propios intereses, y con miras a lograr la verdad de las proposiciones $^{34}$. De esta forma, la actividad probatoria de las partes es siempre necesaria en la legitimación de la decisión judicial pero puede no ser suficiente para alcanzar los fines dispuestos al proceso.

Desde esta perspectiva me parece que la tarea del juez en la recolección del material probatorio es esencial. Y creo visualizar dos motivos: en primer lugar, permite que se ingresen al proceso todas aquellas fuentes de prueba que las partes, por uno u otro motivo, han renunciado a aportar o que han aportado de manera incorrecta cometiendo un yerro en la selección del medio idóneo para introducir una fuente de prueba. El juez, a diferencia de las partes, no hace un ejercicio de valoración hipotética del resultado de la fuente omitida, sino más bien pondera su utilidad y pertinencia para los efectos del proceso. Le es indiferente si tal prueba favorece-

32 Monteleone, Girolamo (2007). "Limiti alla prova di officio nel processo civile (cenni di diritto comparato e sul diritto comparato). Rivista di Diritto Processuale. $\mathrm{N}^{\circ}$ 4, 2007, pp. 863-874, p. 865.

33 TARuffo, Michele (2003). "Investigación judicial y producción de prueba por las partes". Revista de Derecho Universidad Austral de Chile, No 2, Vol. 15, pp. 205-213, p. 209 y ss.

34 Parte de la doctrina ha sustentado un deber de cooperación que pesaría en los litigantes y que podría ser extraído a partir de la buena fe procesal. Un deber de cooperación cuando está en franca contraposición con los intereses de los litigantes resulta al menos cuestionable y difícil de aceptar. 
rá a una u otra parte. Intenta corregir las exageraciones de la utilización del método dialéctico en la recolección del material de conocimiento, puesto que la actividad de las partes al ser eminentemente interesada (y está bien que así sea), puede mitigar las posibilidades de alcanzar la verdad. En segundo lugar, esta prueba sirve para enriquecer el material de conocimiento sobre el que operará el juicio de hecho. Mientras más prueba exista mayor serán los datos informativos utilizables para fundamentar la sentencia. La posibilidad resolver el conflicto sin necesidad de recurrir a la carga de la prueba son mayores si el juez cuenta con la posibilidad de aportar prueba.

Es claro que la iniciativa probatoria del juez no puede garantizar la obtención de la verdad, pero sí contribuye a acercar el proceso a ese ideal. En consecuencia, es una herramienta eficiente para disminuir las posibilidades de error de la decisión judicial, al aumentar el grado de probabilidad de que la decisión se corresponda con lo que efectivamente sucedió ${ }^{35}$.

Por cierto que determinar el momento procesal adecuado para dar al juez la posibilidad de acordar prueba es una decisión que puede venir definida por motivaciones de eficiencia. Parece ser que la posibilidad de adoptar medios de prueba adicionales una vez que han tenido lugar y se ha observado la eficacia o ineficacia de la prueba propuesta por las partes, presta un grado mayor de eficiencia en la obtención de la verdad, puesto que solo así el juez está en condiciones de evitar una decisión fundada en las reglas de la carga de la prueba ${ }^{36}$. Esta actividad probatoria opera en base a la existencia de hechos dudosos, y tiende a excluir la duda en los resultados probatorios.

Sin embargo, la obtención de decisiones verdaderas es una finalidad del proceso que no puede alcanzarse a toda costa o de manera absoluta. El respeto a los derechos de los justiciables juega un papel importante en el reconocimiento y articulación del proceso, y constituye un factor que evidentemente condiciona la posibilidad de acercase al fin ${ }^{37}$. En el ámbito preciso de la actividad probatoria del juez, habrá que ver cómo afecta su imparcialidad, lo que influye en forma determinante en el contenido, oportunidad y límite de la potestad probatoria.

35 TARUfFo (2008) 28 y FerRer, Jordi (2007). La valoración racional de la prueba. Madrid: Marcial Pons, 166 pp., p. 29.

36 Nieva, Jordi (2010) La valoración de la prueba. Madrid: Marcial Pons, 374 pp., p. 188.

37 Ferrer (2005) 31y ss. Es el caso, por ejemplo, de la exclusión de la prueba ilícita. No obstante, también hay otros límites a la obtención de las decisiones verdaderas que no se fundamentan en el respeto en el derecho de los ciudadanos. Es el caso, por ejemplo, de las convenciones probatorias. Se estima que la actividad probatoria no puede ser asumida sobre extremos donde las partes manifiestan su conformidad sobre la verdad de un enunciado fáctico. Esta decisión puede ser eficiente desde el punto de vista económico, pero quizá no desde la decisión verdadera, puesto que las partes no pueden hacer verdadero un enunciado fáctico que no existió, y viceversa. Para una crítica fundada a la obtención de la verdad por medio del consenso: Taruffo, Michele (2008) “¿Verdad negociada?”. Revista de Derecho Universidad Austral de Chile, $\mathrm{N}^{\circ} 1$, pp. 129 a 151. 
En el PCPC es posible advertir que la iniciativa probatoria del juez está orientada a averiguar la verdad, disponiendo como límite a esa potestad el respeto al derecho de defensa (Art. $18 \mathrm{~N}^{\circ} 4$ ). La norma en cuestión es clara en cuanto a su contenido. El juez puede disponer de todos los medios de prueba prácticamente sin ningún tipo de exclusión. De esta forma, nuestro PCPC se proyecta al estilo de su homóloga alemana y francesa al darle al juez un rol activo en la recopilación del material probatorio.

No obstante, hay una serie de extremos que no están claros en este PCPC y que solamente quiero dejar anunciados: en primer lugar, no está claro el momento procesal en que se optó darle iniciativa probatoria al juez. En segundo lugar, no se precisa qué se quiere decir con el respeto al "derecho de defensa". Una primera aproximación podría llevarnos a concluir que el contenido mínimo de este derecho es que las partes puedan producir contraprueba ${ }^{38}$. No obstante, tal conclusión no es exacta en el marco del proyecto, ya que las partes no tienen la posibilidad de producir o solicitar prueba adicional en la audiencia preliminar. En tercer lugar, no resulta del texto legal el carácter complementario de la actividad probatoria del juez, aunque bien puede deducirse de una interpretación razonable de la norma jurídica procesal. Por último, tampoco se establecen límites derivados de la imparcialidad del juez, como la necesidad de limitarse a los hechos previamente alegados por las partes o a las fuentes de prueba que consten del proceso.

Con todo, me parece relevante indicar que la eliminación de las medidas para mejor resolver no está totalmente justificada a los fines de la eficiencia. Si bien gozan de una pésima fama, creo que es posible darles una orientación diferente a la actual. A través de ellas puede permitirse la práctica de los medios de pruebas previamente aportados por las partes pero que resultaron frustrados o que arrojaron resultados inverosímiles.

\section{(3.3) PODERES PROCESALES Y EFICIENCIA DEL PROCESO}

Los poderes procesales o de gobierno del proceso son aquellos que permiten al órgano jurisdiccional gestionar y controlar, en todas las etapas del proceso, sus aspectos formales, relativos al desarrollo procedimental, sin injerir el fondo de la decisión ${ }^{39}$. Dentro de este género es posible distinguir entre aquellos poderes que se refieren al impulso procesal, y a los que se dirigen al control de la legalidad de los actos y de los presupuestos procesales.

\footnotetext{
38 Bordalí, Andrés (2008): "Los poderes del juez civil". En De la Oliva, Andrés y Palomo Vélez, Diego (coordinadores). Proceso Civil. Hacia una nueva justicia civil. Santiago: Editorial Jurídica de Chile, pp. 179-203, p. 195.

39 Montero Aroca, Juan et al. (2007) Derecho Jurisdiccional I. $15^{\circ}$ ed., Valencia: Tirant lo Blanch, 915 pp., p. 346.
} 
En el apogeo de las ideas liberales del siglo XIX estos poderes quedaron confiados exclusivamente a las partes. Se estimó que el interés de los litigantes en la solución de su controversia sería el motor suficiente para darle al proceso un ritmo adecuado. Como el proceso se sustentaba entre dos sujetos libres e iguales y versaba sobre bienes jurídicos privados, ningún interés podía tener el Estado en la solución de esa controversia. Al igual que el funcionamiento del mercado la judicatura jugó un rol pasivo. Mismo razonamiento se predicaba respecto a los actos procesales. Si ellas podían disponer del proceso con mayor razón eran las únicas interesadas en controlar la legalidad de las actuaciones procesales.

Con la Ordenanza Procesal Austriaca de Franz Klein de 1895, comienza a forjarse un nuevo fenómeno dentro del Derecho Procesal Civil, denominado "publificación" o "publicización" del proceso, que influenció buena parte de la codificación europea y latinoamericana de principios y mediados del siglo XX. Este fenómeno, en apretada síntesis, postulaba resaltar el interés público o general que existía con el conflicto judicial, al entender que las disputas, aun versando sobre bienes privados, son desarrolladas por y ante órganos estatales, asumiendo el Estado un interés en el correcto ejercicio de la jurisdicción. De esta constatación puede justificarse un fortalecimiento del papel del juez en la función jurisdiccional, dotándolo de fuertes poderes para desempeñar un rol activo. Esta idea justificó durante largos ańos la asignación de poderes tanto materiales como formales a los jueces civiles ${ }^{40}$.

A mi parecer es evidente que en el desarrollo del proceso hay un interés estatal: el Estado asegura al justiciable que su solicitud de tutela se someterá a un procedimiento legalmente preestablecido. En este procedimiento el Estado compromete buena parte de sus recursos personales, materiales y económicos, y le interesa la utilización racional de los mismos. Desde este punto de vista, creo que los poderes del juez pueden servir para la utilización eficiente de esos recursos mediante dos técnicas.

En primer lugar, reconociéndole al juez un poder para controlar $a b$ initio los denominados presupuestos procesales. Con este poder se evita que el proceso se desarrolle inútil e innecesariamente. El desarrollo íntegro del proceso solo se justifica en la medida que sea útil y necesario ${ }^{41}$. Cuando la pretensión formulada por el ciudadano no cumple con los denominados "presupuestos procesales" (competencia del tribunal, capa-

40 Quizá es esta una de las grandes falacias que ha sostenido parte de la doctrina del Derecho Procesal. No creo que ese interés público pueda justificar los poderes de dirección material, y en especial, la posibilidad de dar iniciativa probatoria al juez. Al respecto, como he tratado de justificarlo, me parece que la decisión por asignar poderes probatorios al juez es una elección de política procesal empapada de nuestras convicciones acerca de la función del proceso civil. Nada tiene que ver el carácter público del proceso.

41 Barbosa, José (1986). "Saneamiento del proceso y audiencia preliminar". Revista de Derecho Procesal. $\mathrm{N}^{\circ} 1$, pp. 7-24, p. 9. 
cidad de las partes, legitimación, procedimiento adecuado, litisconsorcio necesario, interés para accionar, etc.), no es racional exigir que la pretensión recorra todo el iter procedimental. Sería un dispendio importante de recursos tener que soportar íntegramente el desarrollo del proceso para la resolución de un aspecto netamente procesal cuyo control, examen y decisión puede gestionarse ex officio por el juez en etapas prematuras ${ }^{42}$. No cabe duda que la larga, costosa y dura tramitación de un proceso no puede finalizar con una sentencia absolutoria de la instancia.

El segundo aspecto donde los poderes del juez juegan un papel relevante es en el impulso procesal. La idea de que el interés de las partes era el principal motor que impulsa el proceso fue descartada por falaz, ya que la realidad demuestra que esos procesos son lentos y engorrosos, y suelen extenderse temporalmente de manera desmesurada. En este escenario los poderes del juez tienen mucho que decir. El impulso de oficio supone entregar al juez la tarea de ir moviendo el proceso de una etapa a otra, evitando así las denominadas "etapas muertas", caracterizadas por el hecho de que ninguno de los litigantes quería asumir una actitud activa para llevar a término la controversia. Solo cuando existía la amenaza ligada a la sanción por no cumplir con la carga de impulso procesal se asumía una determinada actividad para dar curso al trámite.

Dándole al juez la conducción de los tiempos procesales, y asumiendo un papel activo en el iter procesal, se evita la paralización del proceso y su excesiva duración. La eficiencia del proceso en los tiempos procesales tiene repercusiones que van más allá del cumplimiento del derecho de todos los justiciables a un proceso sin dilaciones indebidas. Así, por ejemplo, en el ámbito contractual las partes de un contrato sabrán de antemano que el tiempo que se emplee en el proceso no será un motivo o incentivo para no cumplir con sus obligaciones.

En consecuencia, los poderes procesales sirven para alcanzar esa idea de eficiencia del proceso entendida como la racional utilización de los recursos públicos.

El PCPC reconoce amplios poderes al juez tanto para controlar $a b$ initio los presupuestos procesales como para impulsar el proceso a su término. En el primer aspecto, se pueden controlar desde la interposición misma de la demanda los presupuestos procesales y, en general, los requisitos formales exigidos por la ley para la "existencia, validez o eficacia del proceso" (artículos $18 \mathrm{~N}^{\circ} 1$ y 236 inciso $2^{\circ}$ del PCPC). Incluso el PCPC da la posibilidad para que el juez rechace in limine una pretensión cuando

42 Esta afirmación es, sin perjuicio, de que la concurrencia de determinados presupuestos procesales puede requerir de un lato conocimiento, y ser el objeto principal de una controversia. Será el caso, por ejemplo, de la competencia del tribunal. Puede discutirse la naturaleza de una relación contractual (civil o laboral) y esa discusión, por sí sola, agota el fondo de la disputa. 
es manifiestamente infundada, potestad que está imbuida de un claro criterio de eficiencia ${ }^{43}$.

En el ámbito del impulso procesal, el Art. 4 del PCPC reconoce un poder amplio y discrecional para que el juez pueda gestionar el andar procesal, ya sea para evitar su paralización frente a maniobras dilatorias de las partes, o para llevarlo a término moviéndolo de una etapa a otra. También se observan ciertos poderes represivos y sancionatorios para las actuaciones de las partes que pretendan dilatar y entrabar el curso normal del proceso (artículos 6 y $18 \mathrm{~N}^{\circ} 10$ ).

\section{(3.4) PODER DEL JUEZ EN LA APLICACIÓN DEL DERECHO Y EFICIEN- CIA DEL PROCESO}

Un extremo que ha brillado por su ausencia en las discusiones acerca de la función del proceso civil y su eficiencia es el relativo a la libertad del juez en la aplicación del Derecho. El problema concreto tiene una doble ramificación. El primero es estrictamente jurídico, y suele presentarse como un simple dilema acerca si el juez es o no libre para aplicar el Derecho al caso sometido a su decisión. Parte de la doctrina -en su mayoría la nacional- que suele enfrentar este tema como uno que mira, esencialmente, a la libertad del juez en la tarea de asignar significados jurídicos a los hechos. De ahí que sea común escuchar que la regla casi absoluta es entender que frente a los hechos le corresponde al juez aplicar el derecho, sin ningún tipo de limitación ${ }^{44}$.

Sin embargo, este no es verdadero problema de la aplicación ex officio de los materiales jurídicos en relación a la eficiencia del proceso. Es jurídicamente imposible restringir o cuestionar la libertad del juez para decidir el conflicto aplicando soberanamente el ordenamiento jurídico. Es esa la esencia de la función jurisdiccional. Tampoco es posible restringir al campo de acción para que el juez pueda examinar la procedencia de una pretensión a la luz del marco legal, por mucho que las partes hayan guardado silencio y no hayan discutido algunos extremos netamente jurídicos de esa pretensión. El asunto es si esa libertad le permite desvincularse de la calificación jurídica para acoger una pretensión con base jurídica distinta a aquella que fue alegada.

La discusión acerca de si el juez es libre en la utilización de los materiales jurídicos ha escapado a la disputa tradicional de los fines del

43 Hunter, Iván (2009). "El poder del juez para rechazar in limine de la demanda". Ius et Praxis. Universidad de Talca. Año 15, No 2, pp. 117-163.

44 Para entender la posición de la jurisprudencia nacional en relación a la aplicación del derecho puede consultarse: HunTer, Iván (2010). "Iura novit curia en la jurisprudencia civil nacional". Revista de Derecho Universidad Austral de Chile. Vol. XXIII N ${ }^{\circ}$ 2, pp. 197-221. 
proceso $^{45}$. El tratamiento de la máxima iura novit curia ha estado estrechamente vinculada a una serie de dogmas que parecen difícilmente cuestionables. Quizá el más poderoso, es aquel que entiende al juez como un conocedor del Derecho, es decir, la presunción de que el juez conoce íntegramente la existencia y significados de los textos normativos. Esta circunstancia, en principio, eximiría a las partes de la labor de alegar y probar los elementos jurídicos de una pretensión, junto con liberar al juez de las alegaciones jurídicas que las partes aducen para fundamentarlas ${ }^{46}$. El otro dogma -que poco interesa para este trabajo- es entender a esta máxima como un principio normativo, por el cual los tribunales y jueces deben aplicar, únicamente, el Derecho.

Ambas ideas están poderosamente ancladas en una determinada función ideológica del sistema jurídico, en virtud de la cual los jueces, al conocer íntegramente el ordenamiento, se limitarían a aplicar las normas jurídicas vigentes que proporcionan otros órganos del Estado, sin ningún poder creativo ${ }^{47}$. Se trataría, al igual que el postulado del legislador racional, de un principio-construcción esencial para el funcionamiento de todo sistema jurídico. Ningún ordenamiento podría funcionar sin suponer que los jueces conocen y describen las decisiones políticas de otros órganos cuando solucionan los conflictos jurídicos.

Esta temática está íntimamente relacionada con la eficiencia del proceso. Si reconocemos al juez un poder amplio en la aplicación del derecho sin vincularlo a la calificación o argumentos jurídicos previamente discutidos por las partes, entonces el proceso tenderá a la eficiencia. El juez nunca podría rechazar una pretensión por estar jurídicamente mal fundada, y todo proceso sería, necesariamente, fructuoso. Por el contrario, si el juez encuentra limitado su poder en la aplicación de los materiales jurídicos reduciéndolo a la posibilidad definir la procedencia de la pretensión (decidir si el derecho está correctamente aplicado), entonces la

45 Aun cuando, afirma Damaska, en principio puede resultar indiferente al modelo o concepción de proceso (como resolución de conflictos o implementación de políticas) la determinación de a quién le corresponde definir los parámetros legales aplicables a la disputa, puesto que siempre sería responsabilidad del tribunal. Sin embargo -continúa el autor-, esta impresión inicial no es tal, ya que mientras más apoyo encuentre el tribunal en las razones jurídicas sustentadas por las partes para definir la cuestión controvertida, ese proceso se acercará en mayor grado a un ideal de resolución de conflictos. El juez decide dentro de los límites jurídicos estipulados por las partes. Por el contrario, una aplicación de la máxima $d a$ mibi factum, dabo tibi ius (denme los hechos y yo, el juez, les daré el derecho) parece más cercana a un proceso destinado a implementar políticas estatales, cuestión que permite justificar que el tribunal pueda sentenciar un caso conforme a una teoría jurídica no planteada por las partes. Véase: Damaska, Mirjan (2000) Las caras de la justicia y poder del Estado: análisis comparado del proceso legal. Traducción de Pablo Ruiz-Tagle U. Santiago: Editorial Jurídica de Chile, 430 pp., p. 197.

46 Ezquiaga Ganuzas, Francisco (2000) "Iura novit curia" y aplicación judicial del Derecho. Valladolid: Editorial Lex Nova, 261 pp., p.18.

47 EzQUiaga (2008) 19. 
posibilidad de que ese proceso culmine con una sentencia desestimatoria es alta, incluso cuando pueda conceder el efecto jurídico pedido bajo otra calificación jurídica. Se comprenderá que el rol que se le asigne al juez en este ámbito resulta esencial para la eficiencia del proceso, puesto que un proceso largo, costoso económica e incluso emocionalmente, no puede estar destinado a resolverse en forma negativa por una incorrecta calificación jurídica de la pretensión.

Sin embargo, el poder del juzgador para aplicar el Derecho tampoco puede ser absoluto. Existen límites que parecen no estar asumidas por la doctrina y jurisprudencia ${ }^{48}$. Cuando el litigio se desarrolla y resuelve en base a las alegaciones jurídicas y calificaciones formuladas por las partes, no hay conflicto de ningún tipo, y ahí es posible afirmar que el juez tiene una libertad absoluta para la definición y aplicación de los materiales jurídicos. Pero, como muy bien observa la doctrina, la desvinculación del juez a los puntos de vista jurídicos sostenidos por las partes en el debate puede ocasionar reparos en relación al derecho de defensa. Estos reparos se centran en lo novedoso y sorpresivo de la calificación jurídica en que se sustenta la condena y respecto de la cual el demandado nada ha podido alegar u objetar durante el proceso ${ }^{49}$.

Desde luego que nadie puede discutir la validez de la "tercera opinión" puesto que no es más que la aplicación del Derecho al caso concreto, un ejercicio puro de jurisdicción. El problema es determinar cómo se puede hacer valer esta opinión sin negar la contradicción de las partes sobre esta nueva tesis ${ }^{50}$. No puede pretenderse que el juez asuma una posición jurídica innovadora frente al derecho, sin que haya dado a las partes la posibilidad de discutir tanto la nueva calificación como los extremos jurídicos que no hayan sido objeto de debate.

Estas complicaciones podrían verificarse en dos casos. Primero cuando el juez cambia o modifica la calificación jurídica contenida en la demanda no habiendo contradicción previa entre las partes. Por ejemplo, cuando el actor plantea una demanda por responsabilidad contractual y el juez, en la sentencia, acoge la pretensión con fundamento en la responsabilidad extracontractual. No cabe duda que esa modificación en tanto no

48 A nivel de jurisprudencia el respeto a la contradicción no se encuentra establecido como límite a la aplicación del derecho por los jueces, quienes se sienten legitimados para decidir aun cuando no haya existido un previo debate sobre los extremos jurídicos. Véase para un análisis más amplio: HunTer (2010) 214 a 216.

49 Ormazábal SÁnchez, Guillermo (2007) Iura novit curia. La vinculación del juez a la califcación jurídica de la demanda. Madrid: Marcial Pons, 135 pp., p. 106.

50 Montero (2001) 323. La posibilidad de recalificar los hechos se encuentra especialmente presente en el proceso penal chileno. Para un buen análisis: Del Río Ferreti, Carlos (2009). "Los poderes de resolución y calificación jurídica en la doctrina jurisprudencial del Tribunal Europeo de Derecho Humanos. Paralelismos con la situación chilena". Revista de Derecho de la Universidad Austral de Chile, Vol. XXII Nº 1, pp. 203-233. 
altere el criterio de relevancia con que se introducen los hechos es perfectamente válida. En realidad el juez corrige una imperfecta invocación del Derecho. Sin embargo, si no ha existido discusión acerca de la naturaleza de la responsabilidad dicho fallo podría catalogarse de incongruente. Lo decidido por el juez no es congruente con lo debatido y discutido en el proceso, con el consiguiente reparado al respeto del derecho de defensa.

El segundo caso donde podría haber una lesión al derecho de defensa se produce cuando el juez se pronuncia sobre algunos de los extremos de la pretensión donde no existió contradicción previa. Por ejemplo, ninguna de las partes discute la existencia de la mera tolerancia en un juicio de precario, pero el juez termina desestimando la demanda por considerar que no concurren dicho presupuesto.

Bajo esta premisa encaja el segundo problema de la máxima iura novit curia y que sí atañe a este trabajo: determinar si razones de eficiencia del proceso permiten justificar la creación de alguna regla procesal que permita someter a la contradicción de las partes una nueva calificación, de manera de evitar una sentencia netamente jurídica que se limite a rechazar la demanda cuando los materiales jurídicos han sido mal invocados. Se trata de hacer efectivo el derecho de defensa de las partes en el debate estrictamente jurídico, con la finalidad de facilitar la dictación de una sentencia que resuelva definitivamente la controversia ${ }^{51}$. Cuando el ordenamiento impide a las partes discutir y reconsiderar los puntos de vista jurídicos iniciales el respeto por la contradicción desarrollada es justificación suficiente para no reconocer una libertad al juez en la aplicación del Derecho. Pero, al contrario, si se da la posibilidad a los litigantes de discutir la tercera tesis o la modificación de la calificación jurídica de los hechos que pretende hacer el juez, entonces no habría inconveniente en reconocer un poder amplio del órgano en la utilización de los materiales jurídicos ${ }^{52}$.

51 Hago presente que si bien toda sentencia definitiva resuelve con vocación de perpetuidad una controversia, cuando esta se basa en una incorrecta aplicación del derecho existe la legítima tentación de renovar la controversia con una nueva demanda centrada en otra calificación jurídica, justificando que entre una y otra no habría una idéntica causa de pedir. Por ejemplo, el fallo determina una responsabilidad del tipo contractual habiendo sido invocada la responsabilidad aquiliana, no cabe duda que existirá la tentación de promover nuevamente esa controversia justificando la pretensión en la otra clase de responsabilidad.

52 Esta fue la propuesta planteada por algunos autores espańoles en la discusión de la LEC $1 / 2000$, al estimar que el problema central de la aplicación del principio del iura novit curia no venía dado en su alcance -el autor supone que el juez debe ser libre para aplicar el derecho, pudiendo cambiar la calificación jurídica contenida en la demanda- sino más bien la forma en que debe procederse cuando el juez pretende dar a los hechos una calificación jurídica distinta a la expuesta en la pretensión. Véase: GARNICA, Juan (1999). "El principio iura novit curia y la determinación del objeto del proceso en el Proyecto de reforma de la Ley de Enjuiciamiento Civil". La Ley: Revista Jurídica española de doctrina, jurisprudencia y bibliografía. Tomo I $\mathrm{N}^{\circ} 1$, pp. 1713-1716, pp. 1714 y 1716. 
Si pensamos al proceso civil como una herramienta eficiente que se destina a dar tutela a los ciudadanos y que debe conciliar el interés de estos con los del Estado, me parece indispensable plantear la necesidad de incorporar en el PCPC algún momento del proceso para que el juez pueda someter al escrutinio de las partes la nueva calificación o argumento jurídico con el que pretende resolver la controversia. El PCPC guarda silencio en este aspecto, por lo que apegarse estrictamente a la exigencia de congruencia no le quedaría camino que rechazar una pretensión cuando el derecho ha sido erróneamente invocado.

A esta solución han arribado los ordenamientos modernos como el alemán y el francés que establecen un mecanismo de contradicción previa para legitimar la decisión que no se base en las alegaciones jurídicas no discutidas, y me parece que es camino correcto para un sistema que se pretenda eficiente.

Quizá la única limitación a la aplicación oficiosa del derecho, previo contradictorio, es el respeto por la petición concreta. Concuerdo con la doctrina cuando dice que el respeto por la disponibilidad de los derechos se refleja en el petitum de la pretensión ${ }^{53}$. Es verdad que el juez en ningún caso puede otorgar una tutela diferente a la pedida. Si así lo hiciera incurría en el vicio de ultra petita. Sin embargo, entiendo que esa petición de tutela sí produce efectos en la aplicación del derecho ${ }^{54}$. Cuando el ciudadano pretende un efecto jurídico afirma la existencia de unos hechos que integran el presupuesto de la norma que fundamenta y hace posible ese efecto. Si el ordenamiento no permite conceder la tutela en base a los hechos alegados entonces el juez queda inmediatamente restringido en su ámbito de aplicación del derecho. Por ejemplo, si el actor califica jurídicamente su pretensión como de error esencial estimando que existe un vicio del consentimiento y solicita la nulidad de un contrato, no puede el juez estimar que esos mismos hechos definen la existencia de un incumplimiento de contrato y resolverlo. La intangibilidad de la petición como manifestación del principio dispositivo sí provoca un efecto delimitador de los materiales jurídicos que se pueden utilizar para conceder la tutela pedida ${ }^{55}$, y sería la única limitación admisible para alcanzar la eficiencia.

Fuera de esta limitación urge incorporar en el PCPC una regla que permita contradecir las tesis jurídicas nuevas o no debatidas, de manera

Así, Ormazábal (2007) 88 y Hunter (2010) 208 y 209.

Hunter (2010) 209.

La distinción entre el poder de aplicar la norma jurídica y de buscar la norma para proceder a aplicarla puede verse en: Millar, Carlos (1983) La incongruencia civil. Madrid: Editorial Tecnos, 211 pp., p. 97. Con todo, el mismo autor reconoce que la doctrina viene predicando hace un par de ańos la necesidad de advertir a las partes la divergencia sobre el punto de vista jurídico, con el fin de evitar no solo sorpresas sino también la posibilidad modificar la defensa cuando hay una mutación jurídica de la pretensión. 
de posibilitar una sentencia estimatoria en base a elementos jurídicos ajenos a la controversia inicial.

\section{CONCLUSIONES}

Todo proceso de reforma debe comenzar preguntándose por los fines que se pretende alcanzar, que no son otros que los fines que se quieren proponer al proceso civil. Esta discusión no precedió al actual PCPC que fue despachado sin una maduración ideológica suficiente. Asumida la importancia de esta materia, la doctrina ha sustentado dos grandes finalidades del proceso: por una parte la que lo limita a la simple resolución de controversias y, por la otra, el que pretende orientarlo hacia la adopción de decisiones justas. En esta última concepción, la obtención de la verdad de los enunciados fácticos asume un papel esencial en la justicia de la decisión, de manera tal que únicamente la decisión que se funda en la verdad es legítima y representa la finalidad del proceso. Se trata de una verdad relativa derivada de la utilidad y extensión epistémica de los medios de prueba.

Con todo, el Estado tiene un interés en lograr una decisión justa basada en la verdad, derivada de exigencias racionales en la valoración de la prueba y del funcionamiento del Estado de Derecho. Es claro que cuando los tribunales aciertan en sus decisiones adjudicando a quien efectivamente cumple con los presupuestos de hecho de la norma jurídica, agrega un incentivo al cumplimiento espontáneo del Derecho. Por el contrario, si nada asegura que el infractor de una ley será efectivamente sancionado por ese hecho entonces decae automáticamente el interés del justiciable de ajustar su conducta a la norma jurídica. De igual modo, las decisiones judiciales se insertan en un escenario general donde lo decidido en un proceso determinado puede tener implicancia directa en otro ámbito; por ende, adjudicar correctamente es indispensable para el correcto funcionamiento de un sistema interconectado.

Sin embargo, frente a la búsqueda de la verdad de las decisiones judiciales como finalidad del proceso se colocan otros fines que también se estiman dignos de ser alcanzados, tales como la necesidad de materializar un proceso sin dilaciones indebidas o uno de un costo económico razonable. Un proceso orientado exclusivamente hacia la verdad es costoso y lento. Es en este contexto los poderes del juez son una herramienta que imprime eficiencia al proceso, al permitir acercarse a la verdad (poderes probatorios) en el menor tiempo posible (poderes de impulso procesal) y con pleno respeto de la legalidad procesal (poderes ordenatorios). Además, y en la medida que se articule un contradictorio previo, permiten que la sentencia pueda justificarse únicamente en la discusión jurídica que las partes han sometido a la decisión del juez, haciendo fructífero todo proceso. 
Los poderes del juez permiten lograr aquel equilibrio entre fines del proceso y eficiencia.

\section{BIBLIOGRAFÍA}

Abel Lluch, Xavier (2005) Iniciativa probatoria de oficio en el proceso civil. Barcelona: Editorial Bosch, 472 pp.

Barbosa, José (1986). "Saneamiento del proceso y audiencia preliminar". Revista de Derecho Procesal. Nº1, pp. 7-24.

BAur, Fritz (1980) La socialización del proceso. Salamanca: Publicaciones del Departamento de Derecho Procesal de la Universidad Salamanca, pp. 7-24.

Bonet Navarro, José (2009) La prueba en el proceso civil. Cuestiones fundamentales. Valencia: Difusión Jurídica, $361 \mathrm{pp}$.

Bordalí, Andrés (2008): "Los poderes del juez civil". En De la Oliva, Andrés y Palomo Vélez, Diego (coordinadores). Proceso Civil. Hacia una nueva justicia civil. Santiago: Editorial Jurídica de Chile, pp. 179-203.

Carratta, Antonio (2001). "Funzione demostrativa della prova (verità del fatto nel processo e sistema probatorio". Rivista di Diritto Processuale. $\mathrm{N}^{\circ} 1$, pp. 73-103.

Cavallone, Bruno (1991) Il Giudice e la prova nel processo civile. Padova: Cedam, 560 pp.

Cortés, Valentín (1983): "La eficacia del proceso de declaración”. En Constitución, Derecho y Proceso. Estudios en memoria de los profesores Vicente Herche Quemada y Ángel Duque Barragues. Zaragoza: Facultad de Derecho Universidad de Zaragoza, pp. 385-408.

Damaska, Mirjan (2000) Las caras de la justicia y poder del Estado: análisis comparado del proceso legal. Traducción de Pablo Ruiz-Tagle U. Santiago: Editorial Jurídica de Chile, 430 pp.

De la Oliva, Andrés (2004) Derecho Procesal Civil. El proceso de declaración. $3^{a}$ ed., Valencia: Editorial Universitaria Ramón Areces, $681 \mathrm{pp}$.

Del Río Ferreti, Carlos (2009). "Los poderes de resolución y calificación jurídica en la doctrina jurisprudencial del Tribunal Europeo de Derechos Humanos. Paralelismos con la situación chilena". Revista de Derecho de la Universidad Austral de Chile, Vol. XXII Nº 1 , pp. 203-233

Devis, Hernando (1967). "La iniciativa probatoria del juez en el proceso contemporáneo". Revista Iberoamericana de Derecho Procesal, No4, pp. 637-662.

(1985): "Facultades y deberes del juez en el moderno proceso civil". En Estudios de Derecho Procesal, Buenos Aires: Zavalia Editores, pp. 257-311. 
Díaz Cabiale, José Antonio (1996) Principios de aportación de parte y acusatorio: la imparcialidad del juez. Granada: Editorial Comares, 578 pp.

Ezquiaga Ganuzas, Francisco (2000) "Iura novit curia" y aplicación judicial del Derecho. Valladolid: Editorial Lex Nova, $261 \mathrm{pp}$.

Ferrer, Jordi (2005) Prueba y verdad en el Derecho. Madrid: Marcial Pons, $111 \mathrm{pp}$.

(2007). La valoración racional de la prueba. Madrid: Marcial Pons, $166 \mathrm{pp}$.

Ferrua, Paolo (2007). Il 'giusto processo', 2a Edición, Bolonia: Zanichelli, 246 pp.

GARNICA, Juan (1999). "El principio iura novit curia y la determinación del objeto del proceso en el Proyecto de reforma de la Ley de Enjuiciamiento Civil". La Ley: Revista Jurídica española de doctrina, jurisprudencia y bibliografía. Tomo I No 1, pp. 1713-1716.

Gascón, Marina (2004) Los hechos en el derecho. Bases argumentales de la prueba. Madrid: Marcial Pons, 232 pp., pp. 125 y siguientes

Hunter, Iván (2009). "El poder del juez para rechazar in limine de la demanda". Ius et Praxis. Universidad de Talca. Año 15, No 2, pp. 117-163.

Hunter, Iván (2010). "Iura novit curia en la jurisprudencia civil nacional". Revista de Derecho Universidad Austral de Chile. Vol. XXIII $\mathrm{N}^{\circ}$ 2, pp. 197-221.

JaÉn Vallejo, Manuel (1989). "El criterio racional en la apreciación de la prueba". Revista de Derecho Procesal. No 1, pp. 69-80, p. 69.

Liebman, Tulio (1960). "Fondamento del principio dispositivo". Rivista di Diritto Processuale, No 4, pp. 551-565.

Millar, Carlos (1983) La incongruencia civil. Madrid: Editorial Tecnos, $211 \mathrm{pp}$.

Monteleone, Girolamo (2007). "Limiti alla prova di officio nel processo civile (cenni di diritto comparato e sul diritto comparato). Rivista di Diritto Processuale. N ${ }^{\circ}$ 4, 2007, pp. 863-874, p. 865.

Montero Aroca, Juan (2000): "Nociones generales sobre la prueba (entre el mito y la realidad". En La prueba. Madrid: Consejo General del Poder Judicial, pp. 15-66.

(2001) Los principios politicos de la nueva ley de Enjuiciamiento Civil. Los poderes del juez y la oralidad. Valencia: Tirant lo Blanch, 190 pp.

et al. (2007) Derecho Jurisdiccional I. 15a ed., Valencia: Tirant lo Blanch, $915 \mathrm{pp}$.

Moreno Catena, Víctor (2001): "Comentario al Art. 282 de la Ley de Enjuiciamiento Civil 1/2000”. En Escribano Mora (coordinador). El Proceso Civil, Vol. II, 6700 pp.

Moreno, Víctor; Contés, Valentín (2004) Introducción al Derecho Procesal. Valencia: Tirant lo Blanch, 319 pp. 
Nieva, Jordi (2010) La valoración de la prueba. Madrid: Marcial Pons, 374 pp.

OrmazÁbal SÁnchez, Guillermo (2007) Iura novit curia. La vinculación del juez a la calificación jurídica de la demanda. Madrid: Marcial Pons, 135 pp.

Picó I Junoy, Joan (1996). El derecho a la prueba en el proceso civil, Barcelona: Bosch Editor, 446 pp.

(2007) El juez y la prueba, Estudio de la errónea recepción del brocardo iudex iudicare debet secundum allegata et probata, non secundum concientiam y su repercusión actual. Barcelona: Bosch Editor, $394 \mathrm{pp}$.

Taruffo, Michele (1990). "Modelli di prova e di procedimento probatorio". Rivista di Diritto Processuale, N² 2, pp. 420-448.

(2002) "Idee per una teoria della decisione giusta". Sui Confini. Scritti sulla giustizia civile, Bolonia: Il Mulino, pp. 219-234.

(2002). "Consideraciones sobre prueba y verdad". Derecho y Libertados Revista del Instituto Bartolomé Las Casas. $\mathrm{N}^{\circ}$ 2, año VII. Madrid: Universidad Carlos III de Madrid. Boletín Oficial del Estado, pp. 99-124.

(2003). "Algunos comentarios sobre la valoración de la prueba”. Discusiones (Publicaciones periódicas), N³, pp. 81-97.

(2003). "Investigación judicial y producción de prueba por las partes". Revista de Derecho Universidad Austral de Chile, №2, Vol. 15, pp. 205-213.

(2007). "Consideraciones entre prueba y motivación". Jueces para la democracia, No 69, pp. 73-80.

(2008) “¿Verdad negociada?". Revista de Derecho Universidad Austral de Chile, $\mathrm{N}^{\circ} 1$, pp. 129-151. (2008) La prueba. Madrid: Marcial Pons, 324 pp. (2009) La prueba de los hechos. $3^{a}$ edición. Madrid: Editorial Trotta, 542 pp., pp. 56 a 87. (2009) Páginas sobre la justicia civil. Madrid: Marcial Pons, 599 pp. 